\title{
The Experiences and Perspectives of Adults with Disabilities in Physical Education Studies
}

\author{
Orly Kayam, Yael Mishani-Uval \\ The Academic College at Wingate, Netanya, Israel \\ Email: orlyka@wincol.ac.il
}

How to cite this paper: Kayam, O., \& Mishani-Uval, Y. (2020). The Experiences and Perspectives of Adults with Disabilities in Physical Education Studies. Advances in Physical Education, 10, 169-186. https://doi.org/10.4236/ape.2020.103015

Received: May 15, 2020

Accepted: June 9, 2020

Published: June 12, 2020

Copyright $\odot 2020$ by author(s) and Scientific Research Publishing Inc. This work is licensed under the Creative Commons Attribution International License (CC BY 4.0).

http://creativecommons.org/licenses/by/4.0/

(c) (i) Open Access

\begin{abstract}
Few studies to date have concentrated on the experiences and perspectives of physical education teachers, interns or coaches with disabilities. The purpose of the current study is to add to a knowledge base that is quite limited by capturing the voice of individuals with physical disabilities or sensory impairments, who trained as certified physical education teachers. Participants include six adults with physical disabilities or sensory impairments (aged 21 33; five men, one woman). Semi-structured in-depth audio-taped interviews were the source of data for the study. Data were analyzed thematically using a six-step process informed by interpretative phenomenological analysis (IPA), through the lens of the Capability Approach. Three central themes were constructed: 1) "disability as a motivating force", which demonstrates the participants' motivation to practice professional sport and to become physical education teachers; 2) "passing it on", which reflects the sense of mission the participants ascribe physical education; and 3) "agents of change" which captures the participants' perceptions of their influence on pupils and their added value to schools. Consequent conclusions and implications regarding the need for more physical education teachers with disabilities are highlighted.
\end{abstract}

\section{Keywords}

Disability, Physical Education, Capability Approach

\section{Introduction}

Extensive research has shown how people with disabilities who are active in sport, can improve their quality of life (e.g. Ashton-Shaeffer et al., 2001; Devine, 2016; Kasser \& Rizzo, 2013; Wilhite \& Shank, 2009; Yazicioglu et al., 2012). Much less research, however, has focused on the experiences, perspectives and feelings of physical education teachers, interns or students with disabilities to- 
wards sports education. The purpose of the current study is to add to a knowledge base that is quite limited by capturing the voices of Bachelor degree students of physical education with physical disabilities or sensory impairments, in order to learn from them about their choice to become physical education teachers, to explore their experiences in teaching or coaching abled-body students ${ }^{1}$ and to examine the way they perceive their influence on pupils.

Due to the paucity of studies focusing on physical education teachers with disabilities, a good starting point to understand the motivation behind their choice of profession is studies examining the experiences of teachers with learning disabilities. Riddick's (2003) study, for example, examined the teaching experiences of 13 teachers with dyslexia, and showed, with regard to their choice of profession, that the majority of the participants felt that their own negative experiences in school had been a strong motivating factor in wanting to give children a better educational experience than their own. Concerning their disability, the study shows that it was perceived by the participants as an advantage, because it enabled them to have greater empathy towards their pupils and a better understanding of their problems.

Burns and Bell (2011) investigated the perceptions of eight teachers with dyslexia, and also found their disability to be integral to their identity as teachers. Their negative experience as pupils also became a motivational source for change, as well as their personal characteristics of persistence, determination, and a strong self-image. In other words, dyslexia was not seen by them as an obstacle but rather as an intrinsic part of becoming the successful teachers they are.

With regard to autobiographical influences on the choice to become teachers, Duquette (2000) found similar results. Examining the perceptions of four students with disabilities (learning disabilities, physical disabilities or low vision), who were enrolled in a 1-year post-graduate teacher education program, Duquette (2000) showed that negative elementary and secondary school experiences were a source of motivation to teach differently than they had been taught. Among other findings, they had accepted their disabilities and possessed specific character traits such as persistence and a strong will to succeed, which contributed to their success.

Research of physical education teachers with disabilities includes an examination of the influence of the teachers on pupils' perceptions of the teachers' competence and of their learning, as well as an examination of the experiences of the teachers (or interns) themselves and the school members or teachers they interact with. Grenier et al. (2014) examined the experience of a physical education teacher intern with a physical disability, and the school members and the students he interacted with. Concerning the question of what is the meaning of teaching for a physical educator with a physical disability, the study showed the teacher's need to distinguish him/herself as a teacher and how the disability itself informed his/her educational narrative. With regard to the influence on the pupils' ${ }^{1}$ Part of the Bachelor degree studies in schools of physical education include teaching practicum at schools. 
perception of disability, it demonstrated how pupils taught by a physical education teacher with a physical disability were able to critically examine cultural assumptions about disability.

Bryant \& Curtner-Smith (2008, 2009a, 2009b) concentrated on how physical education teachers with physical disabilities are perceived by pupils. In their first study of the series (Bryant \& Curtner-Smith, 2008) they randomly assigned 113 elementary school pupils ( 9 - 12 years old) to view one of two videotaped swimming lessons. In the first videotaped lesson the teacher was able-bodied and in the second the same teacher taught from a wheelchair. Everything else was identical. Following the viewing of one of the two lessons, the pupils were asked to complete a questionnaire regarding their perceptions of the teacher's competence and the content of the lesson. Results revealed that pupils learned more about the content of the lesson from the teacher in the wheelchair. Regarding their perceptions of the teacher, there were no significant differences between the two groups.

In a later study, Bryant \& Curtner-Smith (2009b) examined the influence of a teacher with a disability on middle-school pupils' perceptions of the teacher's competence and of their learning. The study included 201 participants in 7 th and 8 th grade (age range 12 to 16 years). This time the results revealed that a physical education teacher with a disability was likely to be at least as effective with, and as accepted by, older middle school pupils as the able-bodied teacher. In a subsequent study, Bryant \& Curtner-Smith (2009a) performed the same experiment, only this time they examined the effect of a physical education teacher's disability on 109 high school pupils' (14 to 18 years old) learning and perceptions of the teacher. The conclusion of this experiment was that while the high school pupils had an equally high regard for the teacher regardless of her apparent physical state, they learned less from her about swimming techniques when she appeared to have a disability than when she was able-bodied.

The findings of the three experiments suggest, as Bryant \& Curtner-Smith (2009a) state, that as pupils grow up their perceptions about physical education teachers with physical disabilities gradually change for the worse, "because they are socialized into believing that sport, physical activity and physical education are for what appear to be whole and fit bodied" (p. 319). This conclusion needs further support, but it suggests the need to integrate such teachers at early stages.

In light of previous findings, mentioned above, and the paucity of studies exploring the experience of physical education teachers with disabilities, many questions still persist. For example, it is far from being clear what motivates individuals with disabilities to pursue such profession, and how they explain their choice to become physical education teachers. Moreover, it is interesting to explore how they perceive their teaching experience at schools and their role as future physical education teachers. The current study aims to fill this gap by focusing on the following research questions:

1) How do physical education teachers, interns or students in physical educa- 
tion teaching programs, with physical disabilities or sensory impairments, perceive their motivation to practice sport and to become physical education teachers?

2) What meaning does teaching physical education with disability hold for them?

3) How do they feel when they teach? How do they perceive their role as future physical education teachers and their influence on pupils?

\section{Theoretical Framework: The Capability Approach}

For the purpose of interpreting and analyzing the data, we used the theoretical framework of the Capability Approach (CA), originally conceived by A. K. Sen, which sees diversity in the human ability to convert the same resources into valuable "functionings" ("beings and doings"). Originally, CA was used to analyze poverty, disability, and gender discrimination (Mitra, 2006). It was also applied to the understanding of disabilities in the context of special needs and special education (Grenier et al., 2014; Terzi, 2005).

CA puts its emphasis on individual achievements, meaning what a person is able to do, and at the same time considers the individual's freedom to realize specific tasks which are central to his/her well-being. It is, therefore, concerned with evaluating an individual in terms of "actual ability to achieve various valuable functioning as a part of living" (Nussbaum \& Sen, 1993: p. 30). According to $\mathrm{CA}$, an individual's capability to live a good life is defined in terms of the set of valuable "beings and doings", such as being in good health or in a good relationship, to which they have real access. Therefore, CA distinguishes between functionings and capabilities (Sen, 1999):

Functionings are "the various things a person may value being and doing" (Sen, 1999: p. 75). "Beings" include examples such as being well-nourished, being in good health, being happy, etc. "Doings" include examples such as walking, reading, and running.

Capabilities refer to the set of valuable functionings that a person has effective access to. In Sen's words, “a person's capability represents the various combinations of functionings (beings and doings) that the person can achieve" (Sen, 1992: p. 40). Thus, a person's capability represents "the real opportunities and freedoms people have to achieve these valued functionings" (Terzi, 2005: p. 449).

The reason we chose to frame our analysis through CA is because this theoretical framework does not consider a disability as a limitation or a restriction of certain everyday activities. Under this approach, the emphasis is on people's freedom "to promote and achieve their own well-being" (Terzi, 2005: p. 445). Therefore, as strongly suggested and performed every day by each one of the participants in the current study, they do not consider their disabilities or impairments as obstacles. One of the participant's (participant B) visual impairment, for example, did not keep him from running marathons or climbing high mountains.

Sen's (1999) concept allows conceptualizing disability regardless of whether it is biological or socially-caused. What matters is the "scope of the full set of capa- 
bilities one person can choose from and the role that impairment and disability play in this set of freedoms" (Terzi, 2005: p. 452). Disability under CA is referred to as "potential disability" (Mitra, 2006: p. 241). At the functioning level, what is important is what the individual wants to do and succeeds in doing. Put this way, disability becomes entirely subjective. "An individual is disabled if he or she cannot do or be the things he or she values doing or being” (Mitra, 2006: p. 241).

Furthermore, Sen develops an additional core concept of agency. An agent is "someone who acts and brings about a change" (Sen, 1999: p. 19). This aspect is important, as Alkire, Qizilbash, \& Comim (2008) highlight, because it allows the assessment of what a person is free to do and achieve in pursuit of his or her meaningful goals (Sen, 1985). Under CA, agency plays a fundamental role in undermining the medical model of disability, which associates a disability with the physical body, and leads, as a result, to the view of people with disabilities as deviations from the norms, and as having a "marked identity" (Grenier, 2007).

\section{Method}

\subsection{Participants}

For the purpose of recruiting participants for the study, the authors contacted the disability center at the college the study was conducted in, and asked for a contact list of all active students with physical disabilities or sensory impairments, who were training at the time at the college as certified physical education teachers. At the time the research was conducted there were five relevant students. One student who had already graduated the college (participant C) was added to the research after consent was given.

Six participants with physical or sensory disabilities, including one female and five male (aged 21 - 33) were requited for the study. At the time the interviews were conducted five participants were active Bachelor students of physical education at the same academic college where both authors work, while one had already completed her studies from this institution.

Participant A $(24)^{2}$ underwent an above-knee amputation due to injury at the age of nine years old, caused during a terror attack. Sports participation-swimming at first - played an important role in helping him to cope with the physical and psychological trauma. At the time of the interview he was a fourth-year student of physical education, and a professional wheelchair basketball player and a distinguished swimmer.

Participant B (33) has been blind from birth. His first experience in sport was riding tandem bicycles, and then he moved on to marathon running. He runs with a sighted guide using a tether. At the time of the interview he was a third-year student of physical education and an athletic coach and a physical education assistant at high school.

Participant C (33) was born with a type of dwarfism. At the time of the interview, she has already finished her studies. She specialized in physical education

${ }^{2}$ The ages of the participants are at the time of the interviews. 
of students with special needs, and works as a sports instructor in a special education school. Participant $\mathrm{C}$ comes from a supportive family that encouraged her to do anything she wanted. As a child she went to floor exercise classes and participated in karate and Thai boxing. She insists on being treated like everyone else, and does not like to be categorized as a person with special needs because, as she puts it best, "I do everything".

Participant D (23) has been deaf from birth. At the time of the interview he was a second-year student of physical education, and has been active in sport since he was seven years old. When he was about nine years old he started playing basketball. During his early twenties he was a physical trainer, and this experience led him to pursue physical education studies.

Participant E (30) is paralyzed in his left leg and arm as a result of a stroke at 17 years old. At the time of the interview he was a fourth-year student of physical education. Before he started the program, he completed a B.A in Communications. During his training as a physical education teacher he started working in an elementary school, as well as working as a trainer of a local youth basketball team.

Participant F (21) has cerebral palsy (CP), and was severely injured when he was 12 years old during a basketball game. At the time of the interview he was a second-year student of physical education. At the age of 16 he joined a youth basketball team. He is a distinguished wheelchair basketball player and a professional swimmer. His dream is to train and advance athletes, with or without disabilities.

\subsection{Data Collection}

The qualitative research was done by means of open-ended in-depth interviews with each of the participants. Assent was received from each participant to be interviewed and audio-taped and to allow the responses to be used for research. The aim of the interviews was to invite the participants to describe their perspectives, experiences and feelings (Smith, 2016) in relation to their experiences as students in physical education studies.

For the purpose of recruiting the participants, the first author, who is acquainted with all students with disabilities as the head of the disability center in the college and as a teacher in the program (in an unrelated field of sports), contacted the participants by phone, and explained the research goals shortly. All six participants agreed to participate in the study. The second author had no previous acquittance with any of the participants. The interviews took place in the first author's office.

Semi-structures, audio-taped, face-to-face interviews were completed by both authors together with each one of the participants separately. The interviews were conducted in Hebrew in the first author's office, using an interview guide developed for the purposes of the research (see Appendix). Interviews lasted from 90 to 120 minutes and were recorded, with the participant's permission.

Each interview session began with the main author introducing herself and 
her co-author by name and position, and describing the general purpose of the study, to expose their positionality as interviewers. More specifically, the first author stated that in addition to her positions in the academic college for physical education, she also does research together with the co-author. Both authors do not have any disability.

\subsection{Data Analysis}

Data were analyzed thematically using interpretive phenomenological analysis (IPA), which has recently become one of the commonly used qualitative methodology to explore personal lived experience and how individuals make sense of that experience (Smith, 2011). The analysis of the interviews was aimed at learning about the participants' cognitive and affective reactions to what was happening to them (Smith, 2011).

After each interview was transcribed by a research assistant, who was not present in the interviews themselves, and checked by the second author against the recordings for accuracy, six stages were utilized in analyzing the data, following suggested procedures by Smith (2016): 1) All transcripts were repeatedly read through by the authors together, while writing and discussing initial insights and observations regarding the transcripts in order to develop a deep and intimate understanding of the content; 2) For each interview, writing comprehensive notes and comments on the data, including descriptive comments focusing on the content of what was said, linguistic comments focusing on the language used by them, including use of figurative language(metaphors, similes, etc.), special use of words or unique expressions, and conceptual comments focusing on more interrogative and conceptual level; 3) Developing a set of emerging themes from the notes and highlighted quotes ordered chronologically for each interview, i.e., in the order they came up; 4) Searching for connections across emergent themes, i.e., organizing the emergent themes in a higher conceptual level of analysis aiming to produce a structure which captures the most interesting and important aspects of the participant's account; 5) Each of the previous stages was done to each of the participants' transcripts, allowing new themes to emerge; 6) The last stage of analysis involved looking for patterns across all cases examined. Overarching themes were compared across all interviews. Recurring themes were labeled.

The Results and Discussion section provides direct quotes to illustrate the issues, and to allow readers to evaluate the authenticity of the claims or interpretations of the participants' descriptions. The selected quotes have been translated into English by the authors. In cases where word-for-word translation did not reflect the intention of the interviewee, the authors took the liberty of translating the intent rather than the literal language of the quote.

\subsection{Trustworthiness}

To ensure trustworthiness, two techniques were utilized during data collection and data analysis. First, each interview began with a description of the purpose 
of the interview and the positionality of the interviewers, as described above. Second, the interviews were semi-structured in order to enable the participants to address the same central issues, but also allow the interviewers to ask follow-up questions that built upon the responses and give the participants the freedom to expand on different issues and elaborate on their responses (Brenner, 2006). This technique allowed the interviewers to clarify information, ask the participants to rephrase and disambiguate unclear statements in real time. It also allowed interviewers to focus on important or central aspects of their experiences, ask for elaboration or examples.

\section{Results and Discussion}

Three primary themes emerged from the data, which capture three dimensions in the participants' perspectives of their experiences of physical education studies and teaching practicum at schools: 1) "disability as a motivating force", which demonstrates the participants' motivation to practice professional sport and to become physical education teachers; 2) "passing it on", which reflects the sense of mission the participants feel with regard to their choice of profession; and 3) "agents of change", which captures the participants' perceptions of their influence on pupils and the added value they bring to the education system and society in general.

\subsection{Disability as a Motivating Force}

While different circumstances led the participants to engage in sport and physical education studies, they all shared similar ideas regarding the therapeutic role of sport in their life and its contribution to their overall well-being. Participant A, for example, started swimming as part of his rehabilitation after the terrorist attack, and he speaks of the water and of swimming as therapeutic, both physically and mentally:

In the beginning, I started with hydrotherapy. It was all about rehabilitation. They told me that it [swimming] would help me and I started and I loved the water... for me it was a kind of detachment. At the hospital I was in a race. People were always around me: volunteers, friends... in the water it was quiet, peaceful... it was something I could connect with... At first sports was for the fun and for rehabilitation, but today I realize it is much more than that. It is mental therapy.

Other participants also spoke of sport as a method for relaxation, for feeling good about their bodies and about themselves, for meditating, and for general well-being. Participant C referred to sport as "the cheap psychologist". Participant $\mathrm{D}$ even ascribed sport an addictive force:

Sport for me is a "drug", it's good, it's positive, it's healthy... When I am doing sport I feel I am in the right place, it brings me happiness, makes me smile. 
Participant $\mathrm{F}$ referred to sport as something that fills his life with purpose and meaning. As he explained, practicing sport and facing the challenges sport poses helped him overcome difficulties and challenges in other areas in life:

Sport is a way of life... it gives satisfaction, the desire to lead, to win... even when I break a record, I'm not satisfied with that and that is what led me to this way of life. When I failed tests I knew how to pick myself up and continue forward... Sport gave me a purpose in life, it's a gift, because without sport I don't even see myself as a student.

This perspective is supported by previous studies showing psychological benefits, such as stress relief, and the importance of an active sport life, for individuals with disabilities (e.g. Blinde \& Taub, 1999; Giacobbi et al., 2008; Kasser \& Rizzo, 2013; Wilhite \& Shank, 2009). Maintaining an active lifestyle is also regarded as beneficial for reducing stress and increasing functional capacity (Giacobbi et al., 2008), and for the functioning of feeling good, active, strong, satisfied, and relaxed.

Under CA, as long as the impairment does not place a restriction on the individual's functionings, in the broader sense as activities or desirable stated (Mitra, 2006), the individual is not to be considered disabled. This captures the participants' view of their impairments. Not only did it not stand in their way to practice professional sport, but practicing sport with it made them feel more capable and free to achieve what they value as meaningful and essential to their well-being. The participants challenge the medical view of disability, which might consider their bodies as imposing restrictions on certain functionings, such as running, swimming, jumping, etc. Pursuing professional sport and physical education enables them to present themselves as athletes and as physical education teachers rather than disabled or "cripples", as Participant F explains:

Sport built my character... sport gave me a way to present myself in society, that I am seen as an athlete and not a cripple.

In terms of CA, The participants' capacity to practice professional sport was their freedom (Sen, 1985). They had the freedom to achieve valued functionings, such as playing basketball, swimming, running, teaching physical education, feeling confident, being happy and in good spirit etc. In this sense, as the participants explain, they did not feel deprived of any capabilities, as Participant $\mathrm{C}$ explained:

I always wanted to be like everyone else... I guess that was the trigger to show everyone that I can... To see people with healthy legs behind you is one of the most enjoyable things.

The participants shared the idea that practicing sport is a way to prove to themselves and to others that their disability does not define who they are. As already established in previous research, physical activity can provide a way to face negative social stereotypes and to empower individuals (e.g. Giacobbi et al., 
2008; Pensgaard \& Sorensen, 2002; Taub et al., 1999). Indeed, the participants explained how good they felt when they had managed to deal with difficulties, to overcome obstacles, to do "the impossible", and to amaze people. Becoming physical education teachers is another way to prove to themselves and to others that they are capable. When Participant A, for example, spoke of his will to become a physical education teacher, he said that standing in front of children or teenagers and teaching them physical education gave him a sense of satisfaction and self-confidence. He felt great that he was able to accomplish what no one would have expected him to be capable of:

It gave me so much... being a physical education teacher; not one person who sees me on the street would ever guess that I am a physical education teacher.

Participant F expressed similar ideas:

Before I began coaching I had had no self-confidence for many years; until I was 18 I used to speak with my head down, and I didn't look people in the eye; it [coaching] simply opened my world. Suddenly as a coach I had a measure of authority, and today it is the best thing that ever happened to me-to coach.

\subsection{Passing It on}

One might wonder why people with physical or sensory disabilities choose to become physical education teachers, which is by nature physically demanding and requires them to face various challenges, such as physical or sensory limitations and pupils' perceptions (see also Grenier et al., 2014; Reina \& Ruiz, 2016). When asked about their choice to become physical education teachers, the participants used words and expressions, which carry the meaning "pass it on". This theme reflects the sense of giving back to society-coming out of oneself for the good of others. They all felt a need to help others experience what sport brings to life. Their own personal experience as disabled athletes made them realize that they can serve as "role models" for children and youngsters, inspiring them to face difficulties, to work hard, to believe in themselves, and to accept differences.

As opposed to the studies, mentioned in the Introduction, showing that negative experiences in school motivated individuals with learning disabilities to become teachers (Burns \& Bell, 2011; Duquette, 2000; Riddick, 2003), the participants of the current study shared the concept of coming out of themselves for the good of others, of their need to give back to society, to pass their good experiences to others. They did not speak of previous negative experiences, but rather about personal positive experiences with sport, that motivated them to pass these feelings on. All participants found great benefits from participating sport and were grateful for the opportunities they received to practice sport and to participate in the physical educators training program. This gave them a sense of mission to help others experience what they have gone through. Participant B, 
for example, explained that he felt a need to make others experience what sport gave him:

I thought that like sports helped me, how can I help young people? I told myself through... training them. I realized that through this I can train, make kids feel more confident, raise their self-esteem, believe in themselves. Like me... the process I went through. Pass it on. That's why I came to learn to be an athletic coach.

Participant C: I felt the need to give back and make other people see that everything is possible - and that this is not just a cliché. It's a cliché and it sounds plucked from the air, but it is really possible.

In this sense, teaching physical education with a disability helps the teachers themselves feel that they are not just being assisted but are also contributing to others, and as a result their sense of capability increases (Flavian, 2010).

Participant E: I see this profession as a mission and a meaningful contribution to society... I also receive a lot of love from the children, and that drives me to continue in this profession despite the low salary.

Some of the participants also spoke of their will to help other groups in society that have special needs, such as elderly people, children with special needs, etc. Participant D, for example, explained:

I am debating between specializing in special education or in heart rehabilitation. Heart rehabilitation interests me because it services patients in hospital, which I find fulfilling. Special education also interests me because it caters to a special population and requires much patience, which I have. Therefore, I feel it is a field where I can contribute and give of myself.

\subsection{Agents of Change}

The third theme explores the way the participants perceive their role as physical education teachers. It captures the dimension of experience where physical education can be, as Evans (2004) suggests, much more than sport and health, but rather concerning the perceptions of the body, ability, and differences among children in school. All of the participants spoke of their profession as a mission. In terms of CA, they considered themselves as "agents of change" in many different aspects.

Having a teacher with disabilities, in the participants' view, sends an important message to pupils that every person faces difficulties and that no one is perfect. It also helps pupils develop a high sense of reflective awareness, acknowledging their abilities and difficulties and developing strategies to face them (Flavian, 2010). Participant A, for example, explained how he serves as an inspiration for determination and willingness to work hard and overcome challenges:

They [the pupils] understand that you can do everything, even if you have some limit or something that prevents you... overcome your flaws, break 
through these walls... I expose them to the world of the disabled, of what it means to be disabled, how to do everything that able-bodied people do but with more difficulty...

In Participant B's view, when pupils see him exercise and work out despite his visual impairment, it encourages them to do better, to overcome difficulties, to face challenges and to make an effort. In his experience, pupils might even feel uncomfortable complaining or giving up because they see their teacher, who has a genuine difficulty, working hard, or in his words:

They don't want me to see them give up, because if I can then they can't show me that they can't. So, yes, it does something to them... Today I taught someone who said to me, forget it, I can't do it, even before she started to run. First of all, I said to her, the minute you say you can't you are telling your brain that you don't want to. Come, let's start, and you'll see that you can do it. She succeeded and I said, you see? She told me, you were right. I asked her to learn from it, not just about running but about everything in life. If you tell yourself "no", then you won't succeed.

Participant C shared similar ideas. She emphasized how her life story and her own achievements changed not only the pupils' perspectives of her and of other people with disabilities, but also her abled-bodied pupils' perceptions of their own capabilities and their approach to difficulties and challenges in life:

They see that I don't give up and I persist until I succeed. I show them what coping is. I tell them that I am small and a physical educator and I didn't get this degree as a present, no way. I worked very hard for it. So I tell them effort pays off. This is why I am there-to change attitudes.

Furthermore, the participants emphasized the added value they feel they bring to schools that physical education teachers without disabilities cannot bring. In accordance with Riddick's (2003) and Duquette's (2000) findings, the participants considered their disability as an advantage that enabled them to show more empathy toward their students, including students with special needs. Almost all of the participants have experienced teaching students with special needs, and in their view, they have the potential to do it better than teachers with no disabilities, because they can better understand what these pupils are facing.

Participant B: I always treat everyone in a straightforward manner, no patronizing or condescending, I treat every child the same no matter what their ability or disability. This year I have one pupil who uses a walker and two with Down Syndrome. The other kids see that I treat everyone the same and they follow my example. Another teacher might not be as sensitive.

Teachers with disabilities, who have experienced difficulties and found ways to deal with them, can also easily detect pupils that have special needs, and are able to offer them coping strategies (Flavian, 2010). They understand the core 
meaning of difference and different types of learning styles. They understand that pupils might need different teaching methods and they are not afraid of differences between pupils. Lienert et al. (2001) report that teachers were concerned about whether they are adequately prepared to effectively teach integrated classes. Taub \& Greer (2000) claim that physical education teachers "frequently exhibit minimal interest in teaching children with physical disabilities and often hold stereotypical perceptions about their abilities" (p. 396). Therefore, physical education teachers with disabilities can better understand pupils with special needs, build up their self-confidence, and also set a personal example that everyone is different, with their own strengths and weaknesses, and that the important thing is to know how to deal with the difficulties and overcome different challenges.

Participant A: I think I understand them better, I have a broader background than others. When I think about my classmates at the college... If they got a class of special needs pupils... they would go crazy! They wouldn't be able to handle it.

Participant F: My advantage is that I know how to use my story to inspire others... to accept the "Other"... every person has some limitation, even if it is not physical... I know how to create a cohesive group and to give that group special tools for coping with life beyond sport. Even if they don't become athletes they will be people.

Creativity is also seen by the participants as a character trait that they acquired as a result of their life experience as people with disabilities. When a physical disability poses challenges to physical education teachers, they have to come up with creative means and methods of teaching. To help his pupils understand the world he lives in as a blind person, participant B teaches his first lesson when his students are blindfolded. He also runs with his pupils tethered to his wrist. Participant A asks pupils to help him demonstrate exercises he cannot perform himself. The need to think of new and creative methods of teaching enriches both the teachers themselves and their teaching methods, and also inspires pupils to be creative, to find creative solutions to different situations, and to open up to new possibilities and new ways of thinking.

Finally, we wish to end with the words of Participant C, which beautifully captures her strong will and sense of purpose to make a difference:

I feel like changing things. Introducing special education to regular schools. I think it makes miracles. A smaller amount, that is obvious, but don't give it a label because labeling closes doors and not everybody has the strength to open them. I hope I can change these two things-empowerment and increasing recruitment to IDF combat units and promoting more integration between special education schools and regular schools... I work in two special education schools and I took my pupils to a competition with regular schools-no one had ever done that before. This is my credo-if we label people then nothing changes and everyone will stay in their separate parallel world and never meet. I think we need to do more. 


\section{Conclusion}

By exploring the perceptions of students with physical disabilities or sensory impairments who are (or were) trained to become physical education teachers, the current study shows physical education teachers with disabilities turn their disability into an advantage and gain a sense of making a contribution to society and of increased self-efficacy. Furthermore, physical education teachers with disabilities feel "agents of change" by exposing able-bodied pupils to disabled bodies, to diversity, and inspiring them to work hard and not give up easily.

The current study also strengthens the view that physical education lessons provide a valuable opportunity to teach much more than sport, all the more so when the teachers themselves have disabilities (Evans, 2004). Physical education teachers with disabilities, as they themselves report, can expose pupils from an early age to differences and imperfections, and to people who overcome their challenges on their own and "do the impossible", and this can have a long-term effect (Brittain, 2004). Physical education teachers with disabilities also inspire pupils to work hard, not give up on their dreams, be creative and open-minded, believe in themselves, and face difficulties (Anderson, 2006).

The current study carries important implications for both individuals with disabilities, for pupils taught by them and for the education system in general. First, the findings of the study highlight the personal benefits physical education teachers with disabilities receive from pursuing such profession, and therefore, imply the importance of encouraging adults with disabilities to participate in physical education studies. Second, the results stress the importance of providing individuals with disabilities an opportunity to contribute to society, feel meaningful and use their life story as an inspiration for children and teenagers. Third, the findings highlight the great influence physical education teachers with disabilities can have on their pupils and their peers, which can have a long-term effect and contribute to building a society in which a disability is not considered an obstacle.

Our hope is that this study will enhance the integration of physical education teachers with physical disabilities or sensory impairments in schools, so that the education system will play a proactive role in raising disability awareness and reducing inequalities within society (Beckett, 2009). Furthermore, we hope that adults with disabilities will be encouraged to pursue physical education as a profession.

\section{Perspectives}

The current study has already borne some fruit. The college in which the research was conducted has taken active steps to help students with physical disabilities or sensory impairment who are part of the training programs of physical education teachers. The most significant one was the establishment of a support center for students with special needs. The center supports any student who needs help as a result of a physical, mental, or learning disability. It offers special com- 
puter programs, tutors that provide one-on-one help or help in small groups, seminars for faculty and staff members, and a special coordinator who is in charge of all students with special needs in the regular program for training physical educators. The coordinator provides an attentive ear to any student with special needs, and serves as a mediator between the students and the college.

\section{Limitations}

Finally, it is important to note that this study is limited in two main respects. First, it is limited in the number of participants, six in total. The reason for the small number of participants is that at the time the interviews were conducted, there were only five active students at the Academic College where the research was conducted, who were relevant to the study, and one graduate student that was added to the study in order to increase the number of participants.

Second, the study focuses solely on the perspectives and experiences of individuals with physical disabilities or sensory impairments, who trained as certified physical education teachers. Future research should also explore the perspectives and experiences of other subjects, including faculty members who have experience in training students with physical disabilities to become physical educators, with their students' peers in the program, and with pupils who have been taught by physical educators with physical disabilities. We hope to complete these challenging tasks in the future.

\section{Acknowledgements}

The authors would like to express their deepest gratitude to Prof. Yeshayahu Hotzler for comments and suggestions on the drafts of the manuscript, and to Dr. Michal Zitomer for early discussions on the study.

\section{Conflicts of Interest}

The authors declare no conflicts of interest regarding the publication of this paper.

\section{References}

Alkire, S., Qizilbash, M., \& Comim, F. (2008). Introduction. In S. Alkire, M. Qizilbash, \& F. Comim (Eds.), The Capability Approach: Concepts, Measures and Applications (pp. 1-25). Cambridge: Cambridge University Press. https://doi.org/10.1017/CBO9780511492587.001

Anderson, R. C. (2006). Teaching (with) Disability: Pedagogies of Lived Experience. Review of Education, Pedagogy, and Cultural Studies, 28, 367-379. https://doi.org/10.1080/10714410600873258

Ashton-Shaeffer, C., Gibson, H. J., Autry, C. E., \& Hanson, C. S. (2001). Meaning of Sport to Adults with Physical Disabilities: A Disability Sport Camp Experience. Sociology of Sport Journal, 18, 95-114. https://doi.org/10.1123/ssj.18.1.95

Beckett, A. (2009). Challenging Disabling Attitudes, Building an Inclusive Society: Considering the Role of Education in Encouraging Non-Disabled Children to Develop Positive Attitudes towards Disabled People. British Journal of Sociology of Education, 30, 
317-329. https://doi.org/10.1080/01425690902812596

Blinde, E. M., \& Taub, D. E. (1999). Personal Empowerment through Sport and Physical Fitness Activity: Perspectives for Male College Students with Physical and Sensory Disabilities. Journal of Sport Behavior, 22, 281-200.

Brenner, M. E. (2006). Interviewing in Educational Research. In J. Green, G. Camilli, \& P. B. Elmore (Eds.). Handbook of Complementary Methods in Education Research (pp. 357-370). Washington DC: American Educational Research Association.

Brittain, I. (2004). The Role of Schools in Constructing Self-Perceptions of Sport and Physical Education in Relation to People with Disabilities. Sport, Education and Society, 19, 77-94. https://doi.org/10.1080/1357332042000175827

Bryant, L. G., \& Curtner-Smith, M. D. (2008). Impact of a Physical Education Teacher's Disability on Elementary Pupils' Perceptions of Effectiveness and Learning. Adapted Physical Activity Quarterly, 25, 118-131. https://doi.org/10.1123/apaq.25.2.118

Bryant, L. G., \& Curtner-Smith, M. D. (2009a). Effect of a Physical Education Teacher's Disability on High School Pupils' Learning and Perceptions of Teacher Competence. Physical Education and Sport Pedagogy, 14, 311-322. https://doi.org/10.1080/17408980802225800

Bryant, L. G., \& Curtner-Smith, M. D. (2009b). Influence of a Physical Education Teacher's Disability on Middle School Pupils' Learning and Perceptions of Teacher Competence. European Physical Education Review, 15, 5-19. https://doi.org/10.1177/1356336X09105209

Burns, E., \& Bell, S. (2011). Narrative Construction of Professional Teacher Identity of Teachers with Dyslexia. Teaching and Teacher Education, 27, 952-960. https://doi.org/10.1016/j.tate.2011.03.007

Devine, M. A. (2016). Leisure-Time Physical Activity: Experiences of College Students with Disabilities. Adapted Physical Activity Quarterly, 33, 176-194. https://doi.org/10.1123/APAQ.2014-0241

Duquette, C. (2000). Examining Autobiographical Influences on Student Teachers with Disabilities. Teachers and Teaching, 6, 215-228. https://doi.org/10.1080/713698718

Evans, J. (2004). Making a Difference: Education and “Ability” in Physical Education. European Physical Education Review, 10, 95-108. https://doi.org/10.1177/1356336X04042158

Flavian, H. (2010). Teacher Training of Students with Special Needs: What Is the Basis of the Discussion and What Is Its Meaning? Mofet Institute Newsletter, 42, 6-11. (In Hebrew)

Giacobbi Jr., P. R., Stancil, M. Hardin, B., \& Bryant, L. (2008). Physical Activity and Quality of Life Experienced by Highly Active Individuals with Physical Disabilities. Adapted Physical Activity Quarterly, 25, 189-207. https://doi.org/10.1123/apaq.25.3.189

Grenier, M. A. (2007). Inclusion in Physical Education: From the Medical Model to Social Constructionism. Quest, 59, 298-310. https://doi.org/10.1080/00336297.2007.10483554

Grenier, M. A., Horrell, A., \& Genovese, B. (2014). Doing Things My Way: Teaching Physical Education with a Disability. Adapted Physical Activity Quarterly, 31, 325-342. https://doi.org/10.1123/apaq.2013-0089

Kasser, S. L., \& Rizzo, T. (2013). An Exploratory Study of Fitness Practitioner Intentions toward Exercise Programming for Individuals with Multiple Sclerosis. Disability and Health Journal, 6, 188-194. https://doi.org/10.1016/j.dhjo.2012.12.002

Lienert, C., Sherrill, C., \& Myers, B. (2001). Physical Educators' Concerns about Integrating 
Children with Disabilities: A Cross-Cultural Comparison. Adapted Physical Activity Quarterly, 18, 1-17. https://doi.org/10.1123/apaq.18.1.1

Mitra, S. (2006). The Capability Approach and Disability. Journal of Disability Policy Studies, 16, 236-247. https://doi.org/10.1177/10442073060160040501

Nussbaum, M., \& Sen, M. A. (1993). The Quality of Life. Oxford: Oxford University Press. https://doi.org/10.1093/0198287976.001.0001

Pensgaard, A. M., \& Sorensen, M. (2002). Empowerment through the Sport Context: A Model to Guide Research for Individuals with Disability. Adapted Physical Actively Quarterly, 19, 48-67. https://doi.org/10.1123/apaq.19.1.48

Reina, R., \& Ruiz, J. A. (2016). Full Inclusion of a Student with Visual Impairment over the Full Physical Activity and Sport Sciences Degree: A Case Study. European Journal of Adapted Physical Activity, 9, 40-52. https://doi.org/10.5507/euj.2016.004

Riddick, B. (2003). Experiences of Teachers and Trainee Teachers Who Are Dyslexic. International Journal of Inclusive Education, 7, 389-402. https://doi.org/10.1080/1360311032000110945

Sen, A. K. (1985). Well-Being, Agency and Freedom: The Dewey Lectures 1984. The Journal of Philosophy, 82, 169-221. https://doi.org/10.2307/2026184

Sen, A. K. (1992). Inequality Re-Examined. Oxford: Clarendon Press.

Sen, A. K. (1999). Development as Freedom. New York: Knopf Press.

Smith, J. A. (2011). Evaluating the Contribution of Interpretive Phenomenological Analysis. Health Psychology Review, 5, 9-27. https://doi.org/10.1080/17437199.2010.510659

Smith, J. A. (2016). Interpretive Phenomenological Analysis in Sport and Exercise. Getting at Experience. In B. Smith, \& A. C. Sparkes (Eds.), Routledge Handbook of Qualitative Research in Sport and Exercise (pp. 241-251). Abingdon-on-Thames: Taylor and Francis. https://doi.org/10.4324/9781315762012

Taub, D. E., \& Greer, K. R. (2000). Physical Activity as a Normalizing Experience for School-Age Children with Physical Disabilities. Journal of Sport and Social Issues, 24, 395-414. https://doi.org/10.1177/0193723500244007

Taub, D. E., Blinde, E. M., \& Greer, K. M. (1999). Stigma Management through Participation in Sport and Physical Activity: Experiences of Male College Students with Physical Disabilities. Human Relations, 52, 1469-1483. https://doi.org/10.1177/001872679905201106

Terzi, L. (2005). Beyond the Dilemma of Difference: The Capability Approach to Disability and Special Educational Needs. Journal of Philosophy of Education, 39, 443-459. https://doi.org/10.1111/j.1467-9752.2005.00447.x

Wilhite, B., \& Shank, J. (2009). In Praise of Sport: Promoting Sport Participation as a Mechanism of Health among Persons with a Disability. Disability and Health Journal, 2, 116-127. https://doi.org/10.1016/j.dhjo.2009.01.002

Yazicioglu, K., Yavuz, F., Goktepe, A. S., \& Tan, A. K. (2012). Influence of Adapted Sports on Quality of Life and Life Satisfaction in Sport Participants and Non-Sport Participants with Physical Disabilities. Disability and Health Journal, 5, 249-253.

https://doi.org/10.1016/j.dhjo.2012.05.003 


\section{Appendix: Interview Questions}

1) When did you first become involved with sports? Are you interested in a particular kind of sport? If so, why did you choose that sport?

2) Was there a specific trigger that led you to engage in sport?

3) What is sport for you? How does the participation in sport make you feel?

4) What has sport given you?

5) When did you decide you wanted to be a teacher, and why did you make that decision?

6) Why did you decide to be a physical education teacher?

7) When did you start your studies at the college? When did/will you finish your studies? What program track are/were you in?

8) Have you already been acclimated as a teacher in a school?

9) How do you feel when you are teaching in a school? How do your students make you feel? Do they give you feedback?

10) How do you feel around other teachers? Do they give you feedback?

11) Do you feel that you contribute something to your students? Something more than sport?

12) Would you encourage other students with physical disabilities to become physical education teachers? 